Benthos Research Vol. 52, No. $1: 47$ - 60 (1997)

BENTHOS

RESEARCH

The Japanese Association of

Benthology

\title{
Vertical distribution and life cycle of two free-ranging polychaetes on a rocky intertidal shore
}

\author{
Keiji Iwasaki \\ Institute for Natural Science, Nara University
}

\begin{abstract}
The vertical distribution and life cycle of two free-ranging polychaetes, Arabella iricolor (Montagu) and Nereis nichollsi Kott, were studied on a rocky intertidal shore at Shirahama, Wakayama Prefecture, where two mussels, Septifer virgatus (Wiegmann) and Hormomya mutabilis (Gould), formed vertically contiguous beds. The abundances of both polychaetes increased downshore within the mussel beds. Multiple linear regression analyses against polychaete density revealed that only shore height tended to be negatively correlated for both species. Adult polychaetes with eggs or sperm in their coelom were collected from May to August for A. iricolor and from April to August for N. nichollsi. Newly settled juveniles ( $<0.5 \mathrm{~mm}$ width) were found abundantly within algal turf formed in the gaps of the H. mutabilis bed in August and September for A. iricolor and in June to September for $N$. nichollsi. No large polychaetes ( $>2 \mathrm{~mm}$ width) of both species were found within the algal turf throughout the year. Many small polychaetes of both species were collected in the H. mutabilis bed in August to December. The cohort increased in size but decreased in density towards the next summer in the mussel bed, and disappeared by October. It appears that both polychaetes have a longevity of one year and reproductive periods chiefly from May to August, followed by recruitment from June to September. Juveniles seem to settle exclusively into the algal turf and migrate with growth into the $H$. mutabilis bed and even the $S$. virgatus bed.
\end{abstract}

Key words: Free-ranging polychaetes, Life cycle, Mussel beds, Rocky intertidal, Vertical distribution

\section{INTRODUCTION}

The ecology of polychaetes has received considerable attention because of their great abundance and influence on benthic communities (reviews by Tamaki 1986, 1993; Thrush 1991). A vast number of ecological studies has been carried out for both free-ranging and tubedwelling polychaetes inhabiting the intertidal muddy or sandy/muddy shores (e. g., Woodin 1974, 1976; Wilson 1981, 1983; Tamaki 1985a, b,

Received August 20, 1996 : Accepted April 25, 1997 c, 1987; Thrush et al. 1989). There are also many studies on the ecology of tube-dwelling polychaetes inhabiting rocky intertidal shores (e. g., Nishi 1993) and coral reefs (Nishi \& Nishihira 1994). Many species of free-ranging polychaetes occur also on rocky intertidal shores (e. g., Glynn 1965), and in particular they exhibit a great abundance within mussel beds (Tsuchiya 1979; Tsuchiya \& Nishihira 1985, 1986; Herwerden 1989; Tokeshi et al. 1989; Ong Che \& Morton 1992; Tokeshi 1995; Iwasaki 1995a). However, their occurrence is local and therefore there have been very few studies on 
their ecology (Tokeshi et al. 1989; Tokeshi 1995).

The present paper reports the vertical distribution and life cycle of two free-ranging polychaetes, Arabella iricolor (Montagu) (Eunicida, Arabellidae) [Japanese name: Seguro-isome] and Nereis nichollsi Kott (Phyllodocida, Nereididae) [Usuzumi-gokai], inhabiting algal turf in the lower intertidal zone and mussel beds of Septifer virgatus (Wiegmann) [Murasaki-inkogai] and Hormomya mutabilis (Gould) [Hibarigaimodoki] (Iwasaki 1995a). Factors affecting the vertical distribution of these polychaetes are discussed with a focus on growth-related migration from the algal turf to the mussel beds.

\section{STUDY STITE AND METHODS}

The study site was a sandstone rocky reef on a moderately wave-exposed shore near the Seto Marine Biological Laboratory, Kyoto University, Wakayama Prefecture $\left(33^{\circ} 42^{\prime} \mathrm{N}, 135^{\circ} 21^{\prime} \mathrm{E}\right)$. The rocky reef had a very smooth, flat surface which sloped gently from the upper intertidal ( $80 \mathrm{~cm}$ above mean tide level) to the subtidal zone with ca. $5^{\circ}$ inclination. Shore height is hereafter expressed in $\mathrm{cm}$ preceded by + or - , i. e. above or below mean tide level. The tidal range at this site extends from +110 to -110 $\mathrm{cm}$. The mussel $S$. virgatus formed an extensive bed from the upper to middle intertidal zone, and $H$. mutabilis in the lower intertidal zone. The two mussel beds were vertically contiguous with a very narrow zone of overlap (Iwasaki 1994). Below the H. mutabilis bed, algal turf 2$3 \mathrm{~cm}$ thick, consisting exclusively of Gigartina intermedia Suringer and Corallina pilulifera Postels et Ruprecht, covered the rock surface of the lower littoral fringe.

The $H$. mutabilis bed accumulated a much greater amount of sediment than the $S$. virgatus bed, presumably due to the greater abundance of byssal threads and tighter mussel-packing in the former (Iwasaki 1994, $1995 \mathrm{a}, \mathrm{b})$. The mussel bed community differed markedly between the two species, and the difference has been suggested to be caused by the differing abundance of sediment (Iwasaki, $1995 \mathrm{a}, \mathrm{b})$. A detailed map of this study site and the zonal distribution of sessile organisms are given in Iwasaki (1994: site B).

To examine the vertical distribution of polychaetes within the two mussel beds, crossshore sampling was carried out at daytime spring low tide in early April of 1982 and 1994. In 1982, two quadrats of $50 \mathrm{~cm}^{2}$ each were haphazardly tossed onto the mussel bed at each of four levels in the $S$. virgatus bed (mean heights for the replicates: $+65 \mathrm{~cm},+38 \mathrm{~cm},+9 \mathrm{~cm}$, and $-6 \mathrm{~cm}$ ) and two levels in the $H$. mutabilis bed ( $-29 \mathrm{~cm},-56 \mathrm{~cm}$ ). Mussels, polychaetes, other invertebrates, and sediment within the quadrats were all collected. In 1994, triple replicate samples were taken at each of five levels in the $S$. virgatus bed (mean heights for the replicates: $+67,+48,+26,+7,-10 \mathrm{~cm})$ and two levels in the $H$. mutabilis bed $(-31,-59 \mathrm{~cm})$. In the laboratory the mussels, polychaetes, other invertebrates, and sediment were sorted under a dissecting microscope, and all animals were preserved in $5 \%$ sea water formalin. The sediment was dried, and after sifting out small shell fragments by using a sieve with $1 \mathrm{~mm}$ mesh openings, it was weighed. The width of the widest segment (the 10th segment for $A$. iricolor and the 5th segment for $N$. nichollsi) of each polychaete was measured. Additionally, the volume of the blotted mussels was measured by putting them into a graduated cylinder with sea water.

Temporal sampling within the mussel beds was carried out at daytime spring low tide monthly from late April, 1982, to late April, 1983 , and at three or four month intervals from late April, 1993, to late December, 1995. At about the middle level of the respective mussel beds $(+35 \mathrm{~cm}$ for the $S$. virgatus bed, $-35 \mathrm{~cm}$ for the H. mutabilis bed), duplicate (1982 1983) and quadruple replicate (1993 - 1995) samples were obtained within each mussel bed. Polychaetes were collected and measured as in the cross-shore sampling described above. Additionally, all polychaetes wider than $1 \mathrm{~mm}$ were dissected under a dissecting microscope, and their state of reproductive maturity was determined by the presence of eggs or sperm in the coelom irrespective of the reproductive stage of the gametes. As described in the results, no polychaetes smaller than $1.5 \mathrm{~mm}$ in width had visible eggs or sperm in both species. Accordingly, the percentage of mature 
individuals in each month was calculated for those wider than $1.5 \mathrm{~mm}$.

The population of $H$. mutabilis at the present study site showed marked fluctuations during the 13 years from 1982 to 1995 (Iwasaki, unpublished data). After growing large from 1982 to 1983 , mussels were dislodged in great numbers due to unknown causes, and the coverage decreased progressively from 1983 . The mussel bed disappeared completely by the summer of 1985. By 1991, the mussel bed had formed extensively again, but it disappeared by the winter of 1994. After the mass dislodgement of $H$. mutabilis, the bare rock surface was covered by algal turf $2-3 \mathrm{~cm}$ thick, consisting exclusively of Gigartina intermedia Suringer and Corallina pilulifera Postels et Ruprecht. Accordingly, the $H$. mutabilis zone contained both mussel beds and algal turf during the period of decline of the mussel population. To compare polychaete density and size structure between the mussel beds and algal turf, sampling within the algal turf was carried out at the ca. $-35 \mathrm{~cm}$ level similarly to that in the $H$. mutabilis beds. On the same dates as for sampling in mussel beds, all algal tufts within a $50 \mathrm{~cm}^{2}$ quadrat were scraped off, and quadruple replicate samples were taken. This sampling was conducted at three or four month intervals from late April,
1994, to late December, 1995. In the laboratory, polychaetes were sorted using sieves with mesh openings of $4,2,1,0.5$, and $0.25 \mathrm{~mm}$ and collected under a dissecting microscope. Polychaetes wider than $1.0 \mathrm{~mm}$ were dissected, and their state of reproductive maturity was determined by the same method described above.

Multiple linear regression analysis against polychaete density was made to detect factors affecting the vertical distribution. Predictor variables were the shore height, the volume and density of mussels and the weight of sediment, the last three of which reflect the complexity of mussel bed structure (Suchanek 1985; Seed \& Suchanek 1992).

\section{RESULTS}

\section{Vertical change in abundance}

In April of 1982 and 1994, the density of $A$. iricolor increased with decreasing shore height (Fig. 1a), the negative correlation being significant (1982: $\mathrm{r}^{2}=0.514,1994: \mathrm{r}^{2}=0.505$, both $\mathrm{p}<$ $0.05)$. The density of $N$. nichollsi also increased downshore in April, 1982 (Fig. 1b, $\mathrm{r}^{2}=0.740$, p $<0.05$ ), but no significant correlation was detected in April, $1994\left(\mathrm{r}^{2}=0.006, \mathrm{p}>0.05\right)$. The density of $N$. nichollsi was less than that of $A$.

\section{a. A. iricolor}

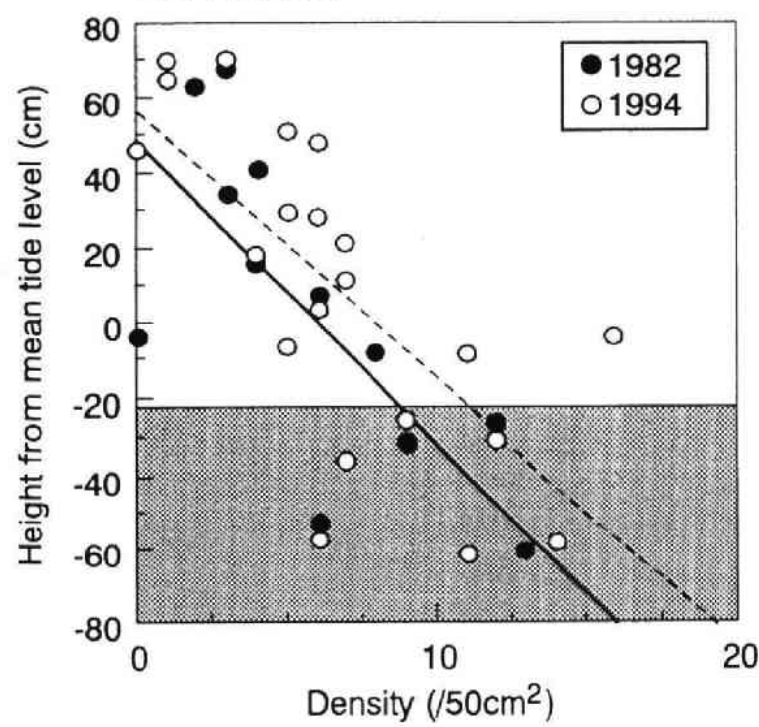

b. N. nichollsi

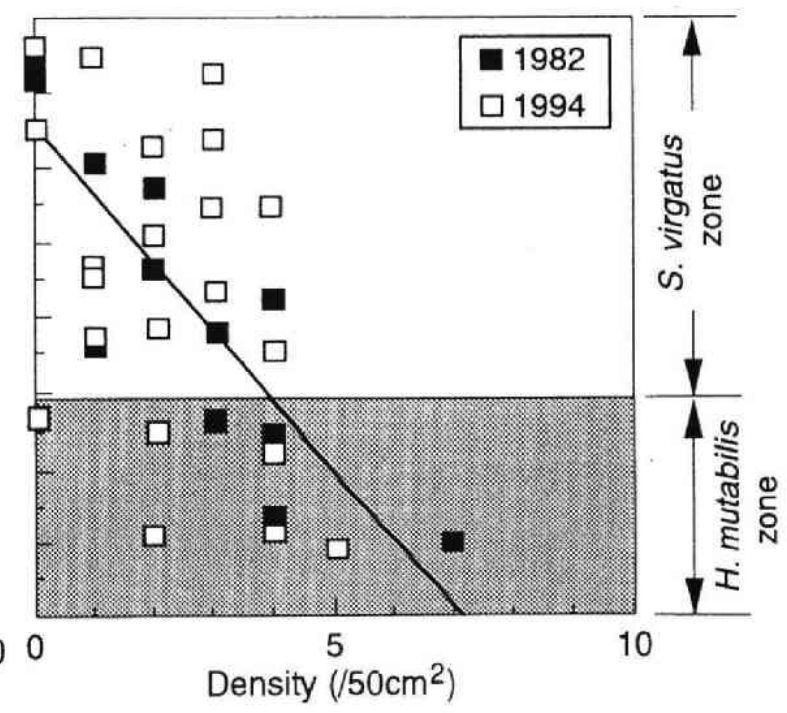

Fig. 1. Vertical change in the density of A. iricolor (a) and N. nichollsi (b) collected from mussel beds in April, 1982 (closed symbol), and April, 1994 (open symbol). 
Table 1. Results of multiple regression analyses against polychaete denisty $\left(50 \mathrm{~cm}^{-2}\right)$ for four predictor variables. Standardized partial correlation coefficients and their probabilities of significance $\left({ }^{n}:\right.$ : not significant at $5 \%$ level, ${ }^{*}:$ significant at 5\% level) are shown together with coefficients of multiple determination $\left(R^{2}\right)$. Mussel density and volume denote summed values for S.virgatus and $H$. mutabilis. Data from 12 samples in April, 1982, and 21 samples in April, 1994.

\begin{tabular}{|c|c|c|c|c|}
\hline \multirow[t]{2}{*}{ Variable } & \multicolumn{2}{|c|}{ A.iricolor } & \multicolumn{2}{|c|}{ N.nichollsi } \\
\hline & 1982 & 1994 & 1982 & 1994 \\
\hline Shore height (cm) & $-0.356^{\mathrm{ns}}$ & $-0.736^{\circ}$ & $-0.892^{\circ}$ & $0.200^{\mathrm{ns}}$ \\
\hline Sediment weight $(\mathrm{mg})$ & $0.344^{n s}$ & $-0.182^{n s}$ & $0.391^{\text {ns }}$ & $0.663^{n s}$ \\
\hline Mussel denisty $\left(50 \mathrm{~cm}^{-2}\right)$ & $-0.324^{n s}$ & $0.180^{n s}$ & $0.310^{\mathrm{ns}}$ & $0.011^{n s}$ \\
\hline Mussel volume (ml) & $0.211^{\text {ns }}$ & $-0.113^{n s}$ & $0.102^{n s}$ & $0.363^{\mathrm{ns}}$ \\
\hline $\mathrm{R}^{2}$ & $0.628^{\text {ns }}$ & $0.566^{\circ}$ & $0.774^{*}$ & $0.273^{n s}$ \\
\hline
\end{tabular}

iricolor on both survey dates. Multiple regression analysis against density revealed a significant negative correlation only with shore height in April, 1994, for A. iricolor, and in April, 1982, for $N$. nichollsi (Table 1).

The size structure of $A$. iricolor differed between the upper and lower parts of the $S$. virgatus bed in April of both 1982 and 1994 (Fig. 2 ). In the upper two shore levels of the bed, the number of small polychaetes ( $<2 \mathrm{~mm}$ wide) was smaller than that in the lower two or three levels, and in April, 1994, the mode of the size distribution tended to become smaller downshore within the mussel bed (Fig. 2b). No marked difference in size structure was detected between the lower $S$. virgatus bed and the $H$. mutabilis bed in either year. In April, 1994, only a few small polychaetes were collected within the algal turf.

The number of $N$. nichollsi collected in the $S$. virgatus bed was small in April, 1982, and it was difficult to compare between the upper and lower parts of the S. virgatus bed (Fig. $3 a$ ). In that month, no significant difference in mean body width was detected between polychaetes collected in the $S$. virgatus bed and the $H$. mutabilis bed $(1.51 \pm 0.43 \mathrm{SD}$ for the former, $1.57 \pm 0.65 \mathrm{SD}$ for the latter, $\mathrm{F}(1,30)=0.64, \mathrm{p}>$ 0.05). In April, 1994, polychaete size differed little among the upper three and lower two shore levels of the $S$. virgatus bed and the $H$. mutabilis bed (Kruskal - Wallis: $\mathrm{H}(3)=0.335, \mathrm{p}$ $>0.05$ ). However, the mode of the size distribution for the upper three levels of the $S$. virgatus bed was larger than that for the lower two levels and for the H. mutabilis bed (Fig. 3b). No large $N$. nichollsi ( $>2 \mathrm{~mm}$ wide) were collected within the algal turf that month.

Seasonal change in density, percentage maturity, and size structure

The density $\left(100 \mathrm{~cm}^{-2}\right)$ of $A$. iricolor in the middle level of the $H$. mutabilis bed varied seasonally from 11 to 37 , increasing abruptly in August, 1982, and decreasing gradually thereafter (Fig. 4). Its density in the middle level of the $S$. virgatus bed ranged from 4 to 13 , a lower value than in the $H$. mutabilis bed throughout the year. No marked seasonal change was detected. The percentage of mature polychaetes wider than $1.5 \mathrm{~mm}$ increased from May to August, and then decreased abruptly to $0 \%$ in September, 1982. This percentage was calculated for individuals collected in both mussel beds.

From April through July, 1982, most $A$. iricolor were wider than $1 \mathrm{~mm}$ (Fig. 5). Adult polychaetes with eggs or sperm in the coelom were collected from May to August, but no individuals smaller than $1.5 \mathrm{~mm}$ in width had gametes. In August, many juveniles smaller than $1 \mathrm{~mm}$ in width were found, but only in the $H$. mutabilis bed. This new cohort increased in size and decreased in number until April, 1983. Polychaetes wider than $2 \mathrm{~mm}$ were very few from September to December, 1982, but appeared again thereafter until April, 1983. Very few juveniles smaller than $0.5 \mathrm{~mm}$ in width were collected within either mussel bed throughout the study period except in August. 
a. April 1982

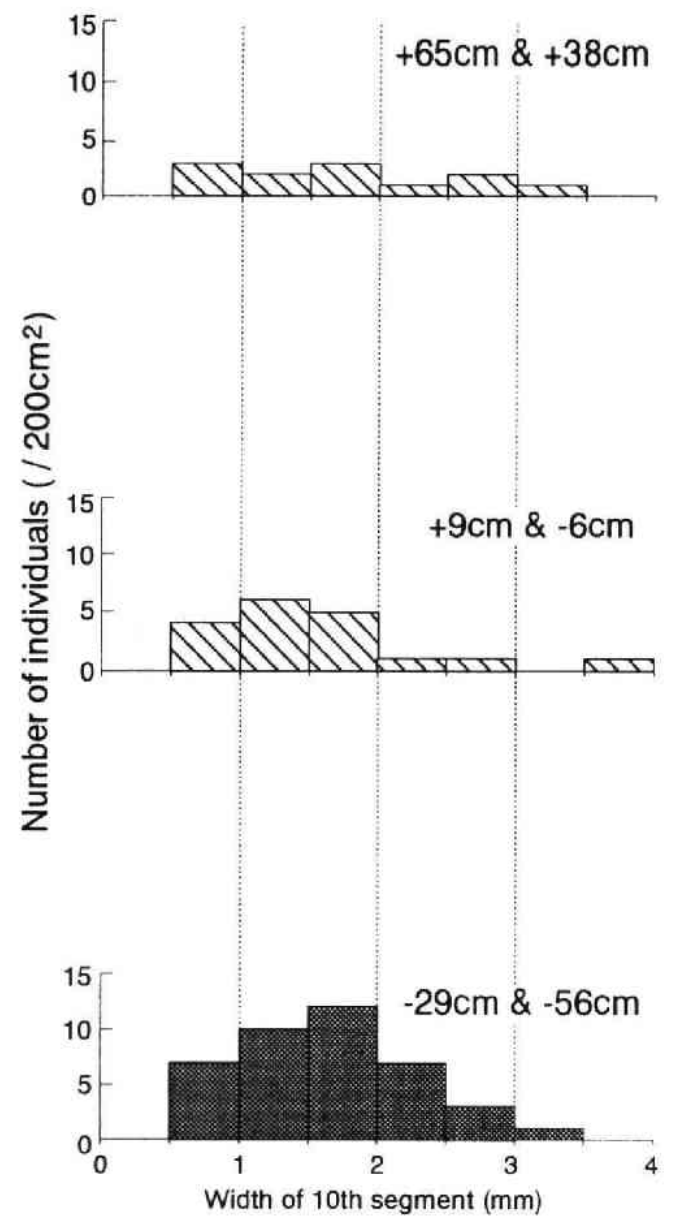

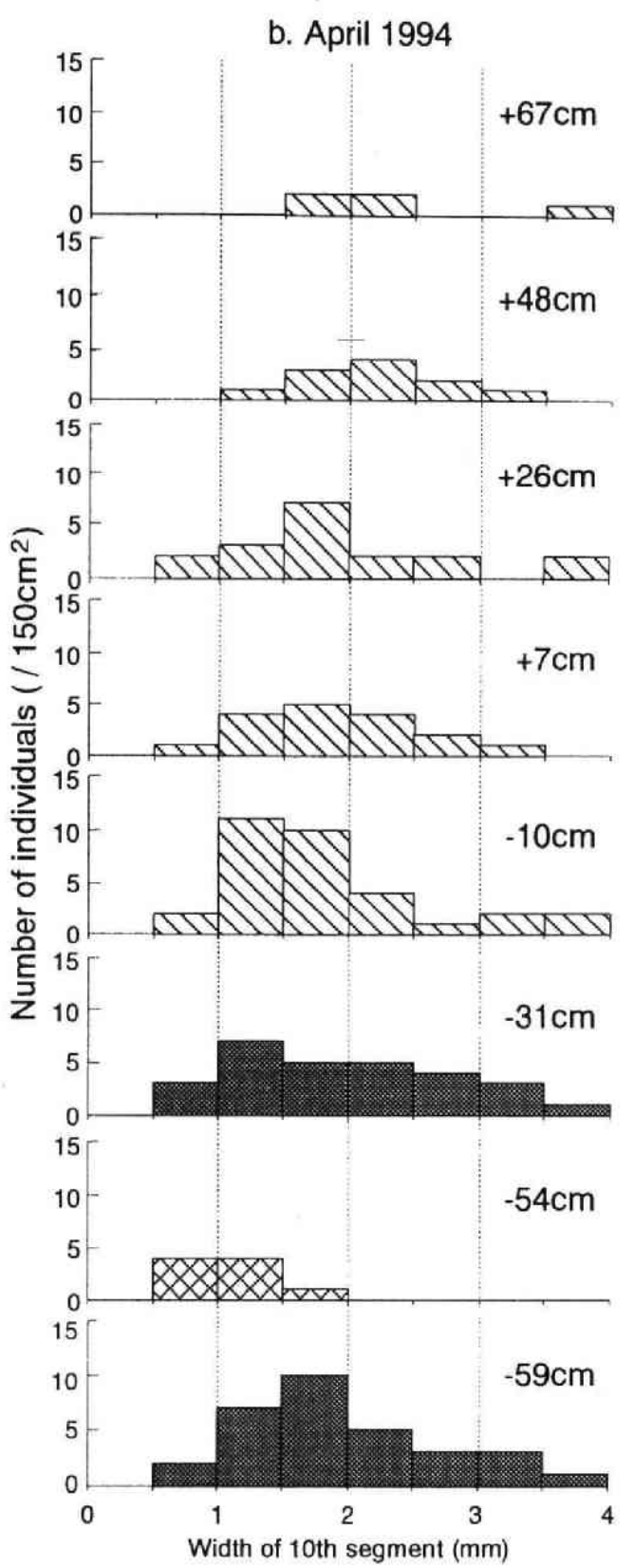

Fig. 2. Vertical change in the size structure of A. iricolor collected at 6 shore levels in April, 1982 (a), and at 8 shore levels in April, 1994 (b). Because of the small number of polychaetes, results of the upper and lower two shore levels of the $S$. virgatus bed (hatched) and two shore levels of the H. mutabilis bed (shaded) in 1982 are lumped. Cross-hatched bars indicate polychaetes collected in the algal turf in April, 1994.

In April, 1993, only middle-sized and large $A$. iricolor wider than $1.0 \mathrm{~mm}$ were collected in the mussel beds, but the polychaetes was not abundant (Fig. 6). In August and December, 1993, there were many small polychaetes with widths of $0.5-1.0 \mathrm{~mm}$ within the $H$. mutabilis bed, and their size structure was similar in both months.
In August, 1994, a great number of juvenile polychaetes smaller than $0.5 \mathrm{~mm}$ in width was collected within the algal turf. This new cohort decreased in number but increased in size from December, 1994, to June, 1995. In March and June, 1995, no juveniles were found within the algal turf. A new cohort appeared again within 

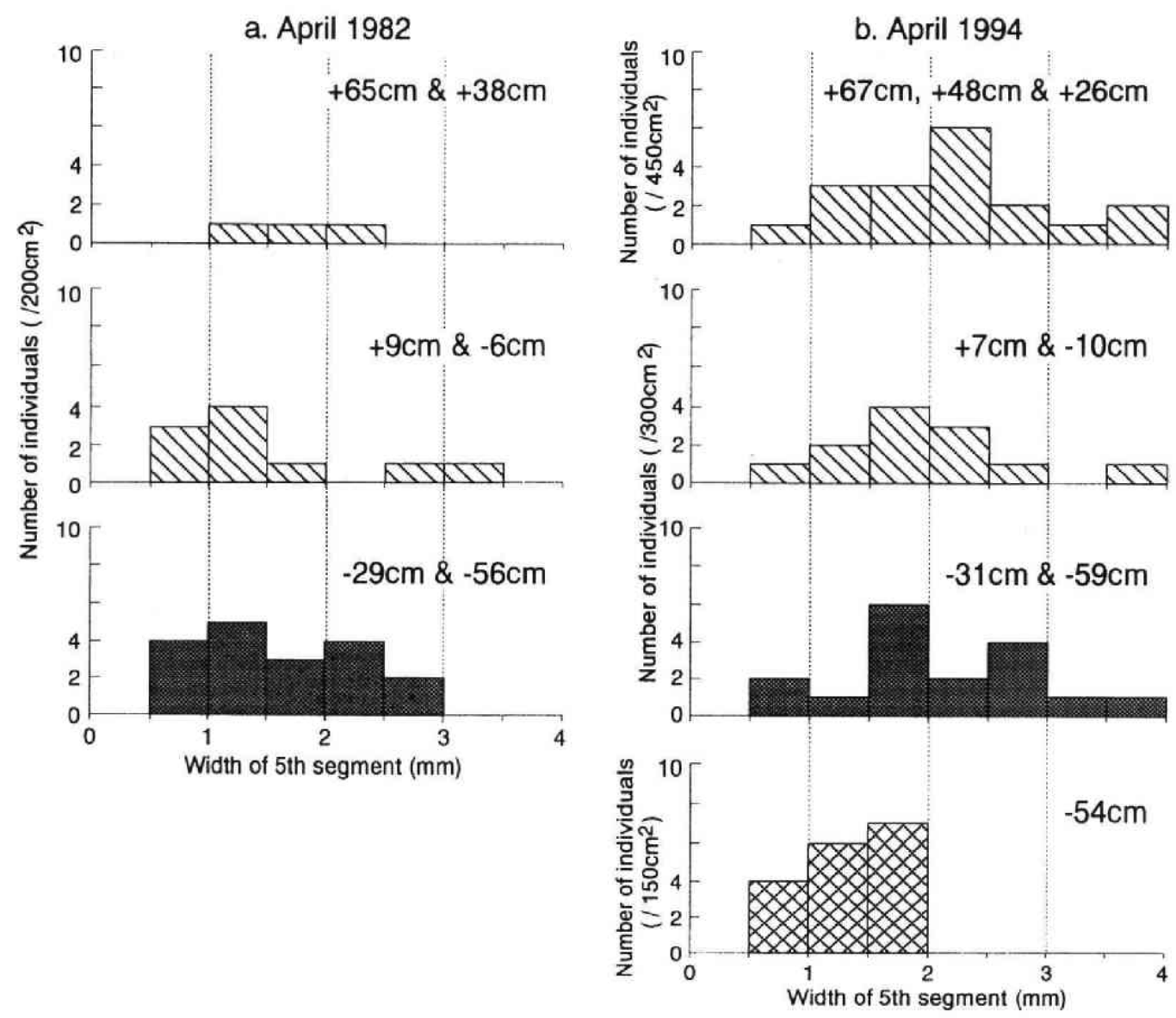

Fig. 3. Vertical change in the size structure of $N$. nichollsi collected at 6 shore levels in April, 1982 (a), and at 8 shore levels in April, 1994 (b). Because of the small number of polychaetes, results of the upper three and lower two shore levels of the $S$. virgatus bed (hatched) and two shore levels of the H. mutabilis bed (shaded) are combined. Cross-hatched bars indicate polychaetes collected in the algal turf in April, 1994.

the algal turf in September, 1995, and juveniles smaller than $1.0 \mathrm{~mm}$ in width were collected abundantly. This cohort decreased in number in December, 1995. Throughout the study period there were very few $A$. iricolor wider than $1.0 \mathrm{~mm}$ within the algal turf, and none of them had visible gametes in the coelom. Within the mussel beds, few juveniles smaller than $0.5 \mathrm{~mm}$ in width were found, and mature polychaetes were collected only in August, 1993, and June and August, 1995.

The density $\left(100 \mathrm{~cm}^{-2}\right)$ of $N$. nichollsi collected in the $H$. mutabilis bed ranged from 5 to 16 and showed no marked seasonal change (Fig. 7). The density in the S. virgatus bed was lower than in the $H$. mutabilis bed throughout the year, and from August to October, 1982, none was found in the S. virgatus bed (Fig. 7).

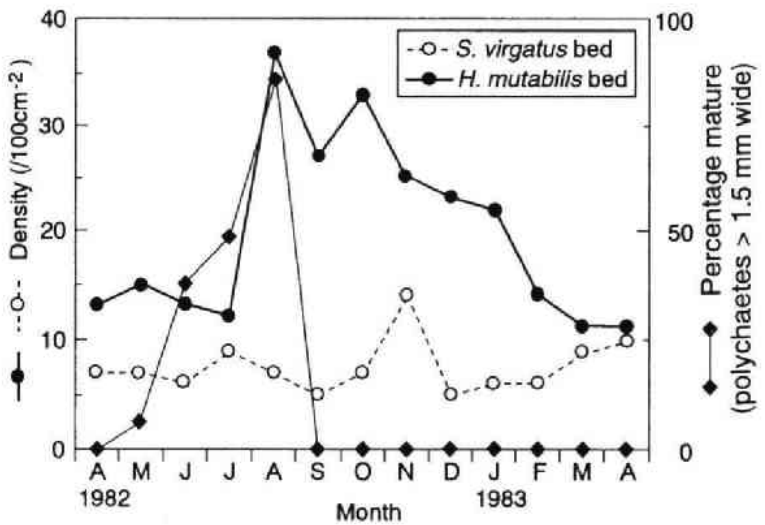

Fig. 4. Monthly changes in density of A. iricolor in the middle levels of the $S$. virgatus bed (open circle) and $H$. mutabilis bed (closed circle), and percentages of mature polychaetes wider than $1.5 \mathrm{~mm}$ with eggs or sperm (closed rhombus, for both mussel beds). 


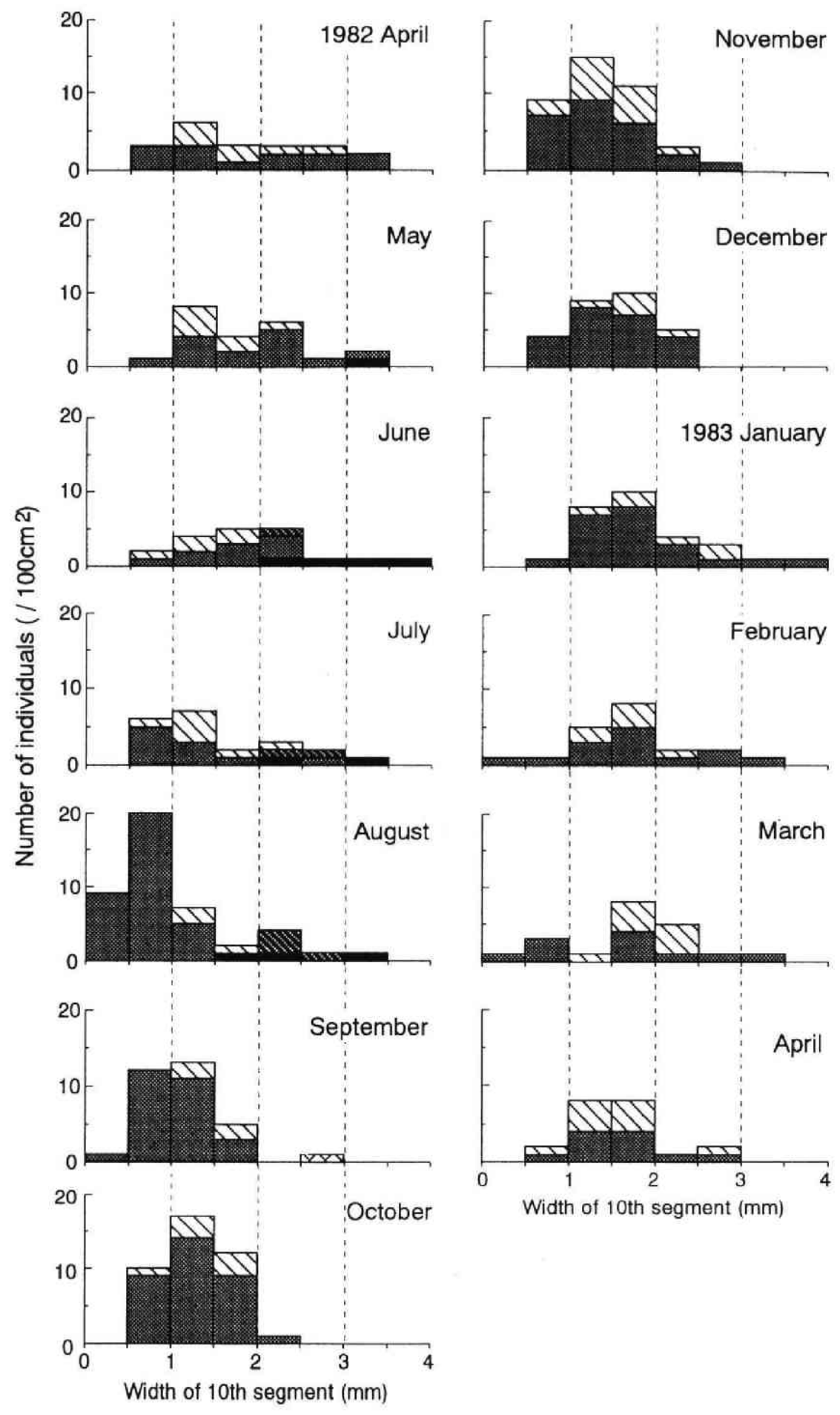

Fig. 5. Monthly change in size (width of 10th segment) structure of $A$. iricolor collected in the middle levels of the $S$. virgatus bed (hatched) and $H$. mutabilis bed (shaded). Thick-hatched and black parts indicate mature polychaetes with eggs or sperm in the $S$. virgatus and $H$. mutabilis beds, respectively. 

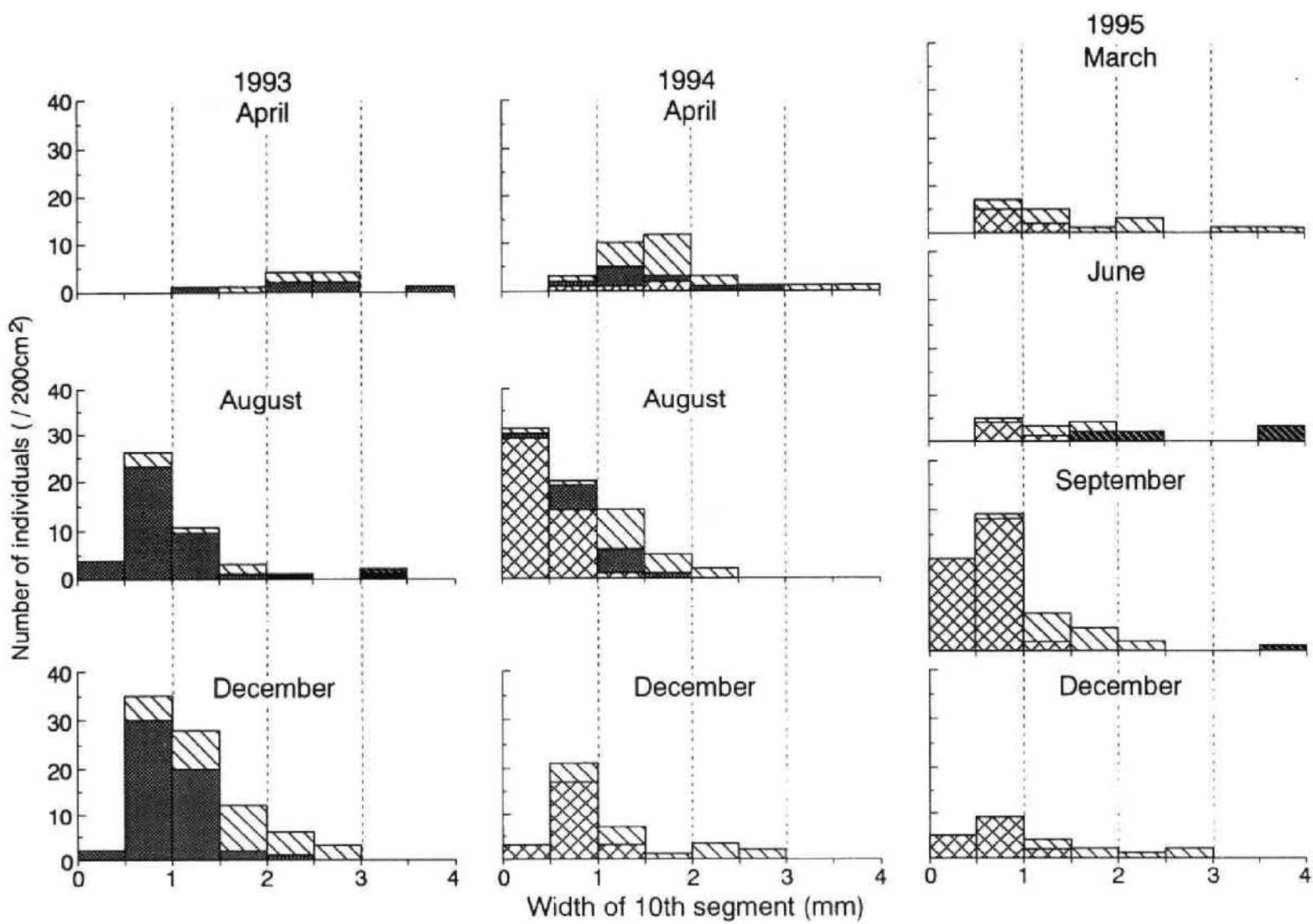

Fig. 6. Seasonal change in size (width of 10th segment) structure of $A$. iricolor collected in the middle levels of the $S$. virgatus bed (hatched, ca. $+35 \mathrm{~cm}$ MTL), H. mutabilis bed (shaded, $-35 \mathrm{~cm} \mathrm{MTL,} \mathrm{from} \mathrm{April,} \mathrm{1993,} \mathrm{to} \mathrm{August,} \mathrm{1994)} \mathrm{and}$ algal turf (cross-hatched, $-35 \mathrm{~cm}$ MTL, from April, 1994, to December, 1995). For key to other symbols, see Fig. 5 . Data from four replicate samples $\left(50 \mathrm{~cm}^{2} \times 4\right)$ for each mussel bed and algal turf. The $H$. mutabilis bed disappeared in December, 1994.

After November, 1982, the density stayed at a higher level than before that month. The percentage of mature polychaetes with gametes increased from May, attained 100\% in July, and decreased thereafter. No mature polychaetes were found from September, 1982, onward.

All N. nichollsi collected from April to June, 1982, were wider than $1.0 \mathrm{~mm}$ (Fig. 8). Mature polychaetes were collected only in the $H$. mutabilis bed from May to August, 1982, but no individuals smaller than $1.5 \mathrm{~mm}$ in width had visible gametes. Juveniles smaller than $1 \mathrm{~mm}$ in width were found from July, 1982, onward, but their number increased in October, due to the recruitment of a new cohort. This cohort increased in size and decreased in number until March, 1983. There were no polychaetes wider than $2.5 \mathrm{~mm}$ in either mussel bed from

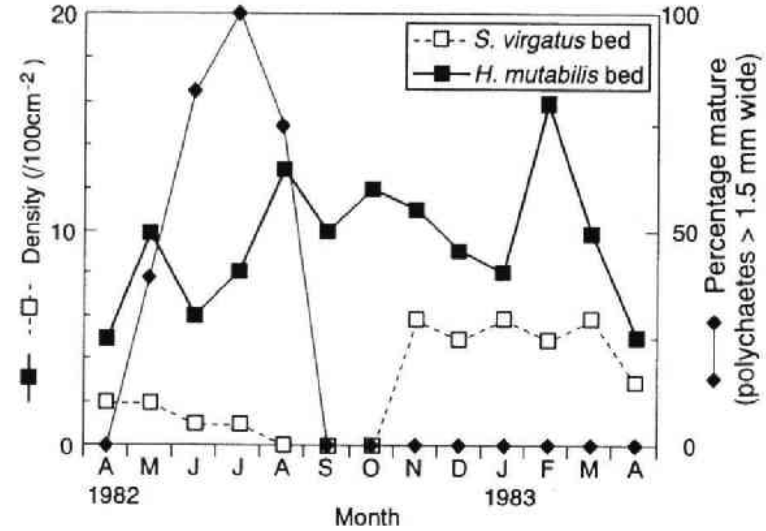

Fig. 7. Monthly change in density of N. nichollsi in the middle levels of the $S$. virgatus bed (open square) and $H$. mutabilis (closed square) beds, and percentages of mature polychaetes wider than $1.5 \mathrm{~mm}$ with eggs or sperm (closed rhombus, for both mussel beds). 


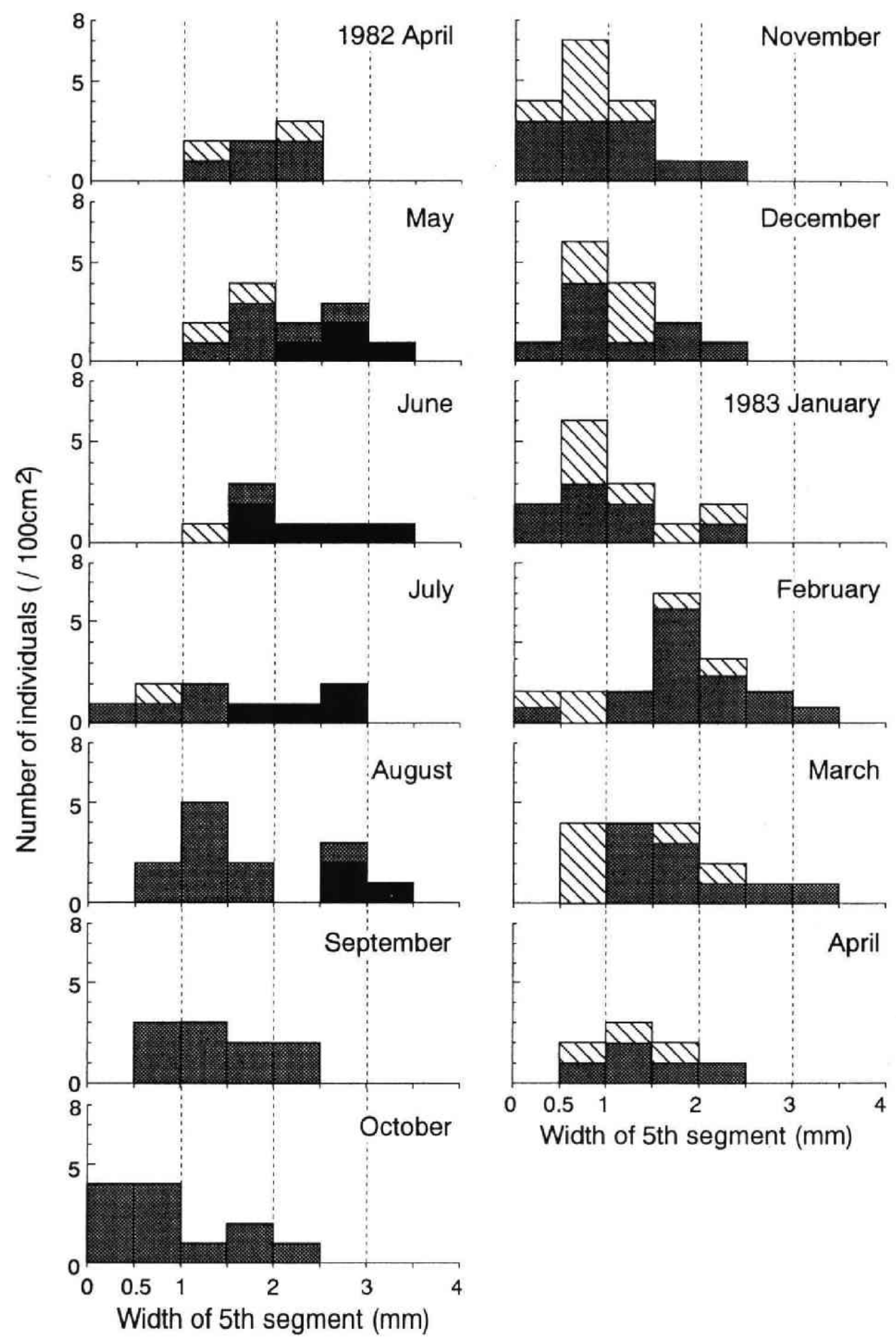

Fig. 8. Monthly change in size (width of 5th segment) structure of $N$. nichollsi collected in the middle levels of the $S$. virgatus bed (hatched) and $H$. mutabilis bed (shaded). For key to other symbols, see Fig. 5 . 

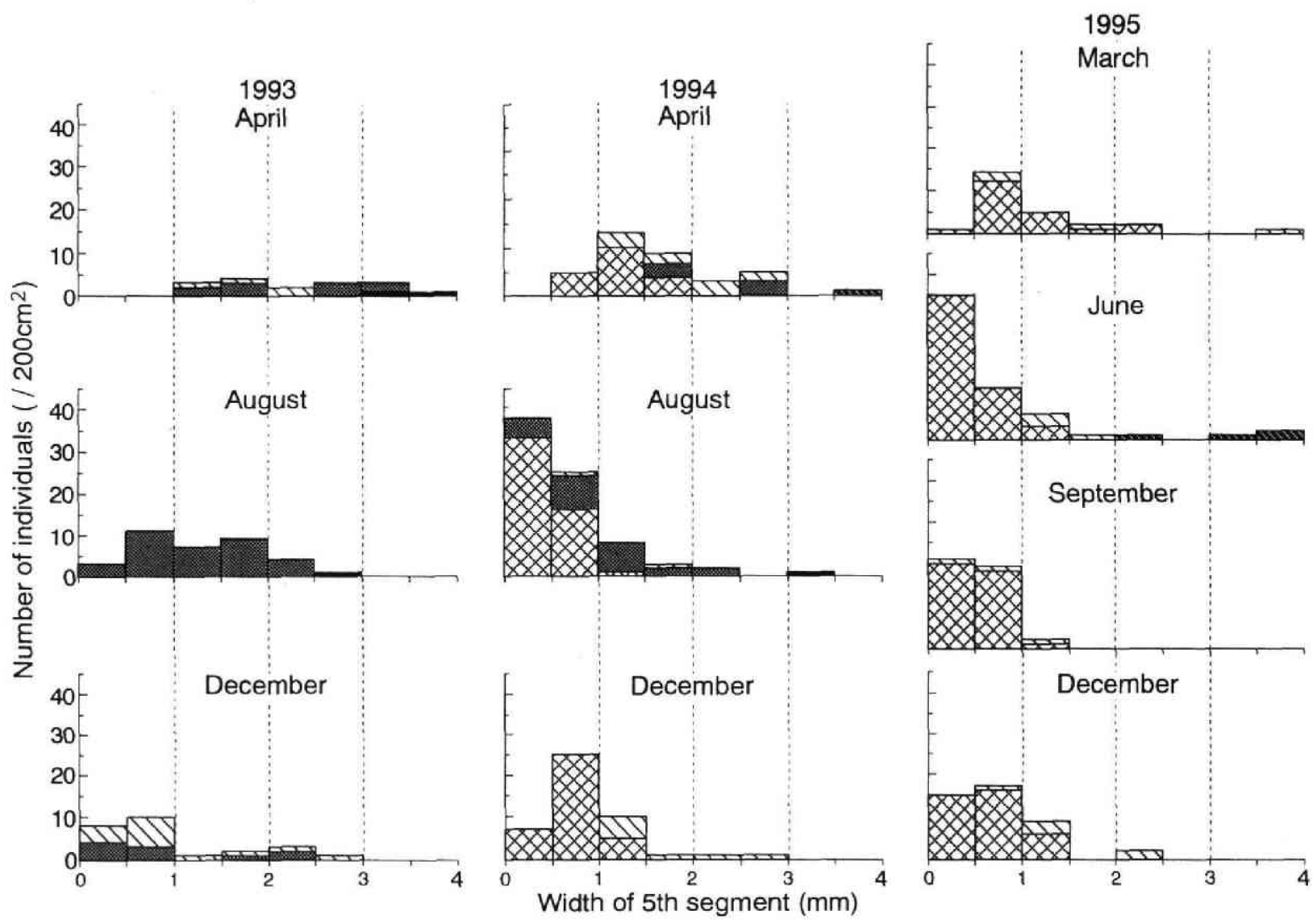

Fig. 9. Seasonal change in size (width of 5th segment) structure of $N$. nichollsi collected at the mid levels of the $S$. virgatus bed (hatched, ca. $+35 \mathrm{~cm}$ MTL), H. mutabilis bed (shaded, ca. $-35 \mathrm{~cm}$ MTL, from April, 1993 to August, 1994) and algal turf (cross-hatched, ca. $-35 \mathrm{~cm}$ MTL, from April, 1994 to December, 1995). For key to other symbols, see Fig. 5. Data from four replicate samples $\left(50 \mathrm{~cm}^{2} \times 4\right)$ for each mussel bed and algal turf.

September, 1982, to January, 1983.

In April of 1993 and 1994, all N. nichollsi collected within the mussel beds were wider than $1.0 \mathrm{~mm}$ (Fig. 9). Newly settled juveniles smaller than $0.5 \mathrm{~mm}$ in width were found abundantly within the algal turf in August, 1994 (Fig. 9), and thereafter this new cohort decreased in number but increased in size until March, 1995. In June, 1995, juveniles were collected abundantly again within the algal turf, and this cohort also decreased in number but increased in size until December, 1995. As in A. iricolor, there were few $N$. nichollsi wider than $1.0 \mathrm{~mm}$ within the algal turf, and none of them had visible gametes. Very few juveniles smaller than $0.5 \mathrm{~mm}$ in width were collected within the mussel beds throughout the study period. Mature polychaetes were found in April and August of 1993 and 1994, and in June, 1995.

\section{DISCUSSION}

Life cycle

Adult $A$. iricolor with gametes were found only in May to August (Figs. 4 - 6). Juvenile A. iricolor smaller than $0.5 \mathrm{~mm}$ in width were collected abundantly only within algal turf in the lower intertidal zone from August to December (Fig. 6). This cohort increased in size and decreased in density within the mussel beds until the next summer (Figs. $4-6$ ), and large $A$. iricolor wider than $2.0 \mathrm{~mm}$ disappeared by October. These results suggest that $A$. iricolor had a longevity of one year with one reproductive period from May to August, followed by juvenile recruitment exclusively into the algal turf from August to September.

The life cycle of $N$. nichollsi seems to be very similar to that of A. iricolor (Figs. 7 - 9), but 
this species may have reproduced even in April, a little earlier than $A$. iricolor, because mature individuals were found in April of 1993 and 1994 (Fig. 9) and because juvenile $N$. nichollsi smaller than $0.5 \mathrm{~mm}$ in width were collected abundantly even in June within the algal turf (Fig. 9).

Polychaetes exhibit many reproductive strategies (Clark \& Olive 1973; Olive 1982; Okada \& Koshida 1983), and factors inducing settlement of their pelagic larvae have been studied by many authors (e. g., Schroeder \& Hermans 1975). Preferential larval settlement onto algae has been reported for several species of sessile, tube-dwelling polychaetes (e.g. De Silva 1962; Williams 1964; Clark \& Olive 1973). However, there has been no similar study for free-ranging polychaetes.

A specific relationship between free-ranging polychaetes and algae has been reported for a lumbrineridid, Lumbrineris latreilli. This species spawns eggs in a jelly mass onto sea weeds on rocky shores (Nishihira et al. 1980, 1981, 1983). Juveniles emerge directly from the jelly mass (Sato et al. 1982) and disperse passively, but recruitment occurs in limited areas near the spawning sites (Nishihira et al. 1984). At the present study site, no such egg mass was found on the algal turf, and no information on the reproductive habits, mode of larval development, and food habits of juveniles of either $A$. iricolor or $N$. nichollsi has been available to date.

The present study suggests that algal turf in the lower intertidal zone are favorable for the recruitment and survival of the early stage of these polychaetes. The algal tufts comprising the turf have wet, wide surfaces and form a minute but complex secondary space on the rock surface. Minute snails, bivalves, amphipods, and polychaetes of other species also inhabit the algal turf in great abundance (Iwasaki, unpublished). Accordingly, the algal turf provide the juvenile polychaetes with food resources and a refuge from desiccation, predation, and wave action. However, the algal turf are evidently not a requisite for the growth of middle-sized and large polychaetes because few individuals wider than $1.0 \mathrm{~mm}$ were collected within the turf throughout the study (Figs. 5, 6, 8, 9). Although a few polychaetes may have settled directly into the mussel beds and grown in place (Figs. 5, 6, 8, 9), migration from the algal turf to the mussel beds must have occurred concomitant with the growth of most of the polychaetes. Experimental studies are needed to demonstrate preferential larval settlement onto the turf and growth-related migration.

\section{Vertical distribution}

Sampling of polychaetes in the present study was carried out at daytime spring low tide. If the polychaetes move up and down following tidal fluctuations, the vertical distributions shown in Fig. 1 represent the situation only during daytime emersion. No information on their vertical movement has been available to date. However, the vertical distributions during emersion consistently showed density of polychaetes increasing with decreasing shore height (Fig. 1). Among the four predictor variables for the multiple regression analyses, only shore height tended to be correlated significantly with polychaete density, and other variables reflecting the complexity of mussel beds had no correlation with density (Table 1 ). These results suggest that some factor, the intensity of which changes with shore height, affects the abundance of polychaetes at low tide.

No marked difference in polychaete size structure was detected along the tide level gradient (Figs. $2 \& 3$ ). However, the mode of the size distribution for both polychaete species collected in the upper part of the S. virgatus bed tended to be greater than those in the lower part and in the H. mutabilis bed (Figs. $2 \mathrm{~b} \&$ $3 \mathrm{~b})$. This also suggests the presence of some factor which both affects polychaete size and is associated with the tide level gradient.

Mussel beds have structural complexity in terms of the surface area of the shell valves, the amount of byssal threads, and presence of organic (faeces and pseudofaeces) and inorganic (sand and silt) particles (Suchanek 1985; Seed \& Suchanek 1992). The H. mutabilis bed accumulates a much greater amount of sediment than the $S$. virgatus bed, presumably due to the dense byssal thread network and tight musselpacking in the former bed (Iwasaki 1994, 1995a, b). The sediment seemed to have a negative effect on the abundance of minute bivalves and isopods inhabiting the mussel beds (Iwasaki 
$1996 \mathrm{a}, \mathrm{b})$. In the present study, however, no negative effect of the sediment was detected on the two polychaetes' abundance (Table 1), suggesting that both species had considerable tolerance to the sediment.

The complexity of mussel beds provides infaunal animals with a variety of microhabitats, and thus mussel beds harbour a large number of animal species (Suchanek 1985; Seed \& Suchanek 1992; Tsuchiya \& Nishihira 1985, 1986). Beds of $S$. virgatus and $H$. mutabilis are no exception (Iwasaki 1995a). At night low tide, large $A$. iricolor were frequently found consuming small mussels and barnacles, which were presumably killed by the great amount of gelatinous mucus secreted by the polychaetes (Iwasaki, unpublished). Small and large $N$. nichollsi were observed attacking small isopods in the laboratory (Iwasaki, unpublished), and small crustaceans do live abundantly in the mussel beds (Iwasaki 1995a). However, the algal turf harbour abundant but minute invertebrates of relatively fewer species than either mussel bed (Iwasaki, unpublished). Accordingly, both mussel beds provide the large polychaetes with abundant food resources. This may be responsible for the growth-related migration from the algal turf to the mussel beds, and upward dispersal from the lower intertidal algal turf can explain the gradational change in polychaete density (Fig. 1) and size structure (Figs. 2b, 3b).

Desiccation may also be an important factor affecting the polychaetes' vertical distribution. Desiccation has profound negative effects on the abundance of many intertidal organisms (e.g., Iwasaki 1995b), and its intensity is thought to increase monotonically with increasing shore height (e.g., Underwood 1978). The relative humidity within the $S$. virgatus bed is much higher than in air above (Ohsako et al. 1981), and both mussel beds can provide their small inhabitants with shelter from desiccation. However, considering their soft bodies and free-ranging habits, both polychaete species are most likely subject to the effect of desiccation even within the mussel beds.

Tokeshi et al. (1989) and Tokeshi (1995) revealed a pattern of spatial coexistence of two free-ranging polychaetes inhabiting mussel beds but presented little information on their interspecific interactions. Also in the present study, the interspecific interactions, feeding habits, and food preferences of both species were not investigated. Studies on these subjects are in progress.

\section{Acknowledgements}

I am indebted to Ryouhei Yamanishi for his species identification, to Laboratory of Animal Ecology and Seto Marine Biological Laboratory, Kyoto University, for their courtesy of giving me facilities for laboratory equipments, and to two referees for their valuable comments and advice.

\section{REFERENCES}

Clark, R. B. and P. J. W. Olive 1973 Recent advances in polychaete endocrinology and reproductive biology. Oceanography and Marine Biology Annual Review, 11:175-222.

De Silva, P. H. D. H. 1962 Experiments on choice of substrate by Spirorbis larvae. Journal of Experimental Biology, 39:483-490.

Glynn, P. W. 1965 Community composition, structure and interrelationships in the marine intertidal Endocladia muricata - Balanus glandula association in Monterey Bay, California. Beaufortia, 12:1-198.

Herwerden, L. V. 1989 Collection of mussel worms Pseudonereis variegata for bait: a legislative anachronism. South African Journal of Marine Science, 8:363-366.

Iwasaki, K. 1994 Distribution and bed structure of the two intertidal mussels Septifer virgatus (Wiegmann) and Hormomya mutabilis (Gould). Publications of the Seto Marine Biological Laboratory, 36:223-247.

Iwasaki, K. 1995a Comparison of mussel bed community between two intertidal mytilids Septifer virgatus and Hormomya mutabilis. Marine Biology, 123:109-120.

Iwasaki, K. 1995b Factors delimiting the boundary between vertically contiguous mussel beds of Septifer virgatus (Wiegmann) and Hormomya mutabilis (Gould). Ecological Research, 10:307-320.

Iwasaki, K. 1996a Vertical changes in density, size structure and shell shape of the bivalve Lasaea undulata within intertidal mussel beds. Journal of the Marine Biological Association of the United Kingdom, 76:417-430.

Iwasaki, K. 1996b Vertical distribution and life cycle of 
two isopod crustaceans within intertidal mussel beds. Benthos Research, 51: 75-86.

Nishi, E. 1993 Ecological study of a sessile polychaete Pomatoleios kraussii (Baird) (Serpulidae, Sedentaria) at Haneji Inlet, Okinawa, with fouling species composition there. Biological Magazine, Okinawa, 31:29-40. (In Japanese with English abstract)

Nishi, E. and M. Nishihira 1994 Colony formation via sexual and asexual reproduction in Salmacina dysteri (Huxley) (Polychaeta, Serpulidae). Zoological Science, 11:589-595.

Nishihira, M., M. Tsuchiya and M. Sato 1980 Ecological aspect of the breeding of the polychaete, Lumbrineris latreilli (Audouin et Milne-Edwards) at Asamushi, northern Japan. Bulletin of the Marine Biological Station of Asamushi, Tohoku University, 16:201-212.

Nishihira, M., M. Tsuchiya and M. Sato 1981 Distribution and spawning site selection of the polychaete, Lumbrineris latreilli (Audouin et Milne-Edwards) at Asamushi, northern Japan. Bulletin of the Marine Biological Station of Asamushi, Tohoku University, 17:17-28.

Nishihira, M., M. Tsuchiya and M. Sato 1983 Ecological aspects of breeding behaviour and juvenile dispersal of the polychaete, Lumbrineris latreilli (Audouin et Milne-Edwards) at Asamushi, northern Japan. Benthos Research, 24:24-33.

Nishihira, M., M. Tsuchiya and M. Sato 1984 Dispersal and recruitment of juveniles of the polychaete Lumbrineris latreilli (Audouin et Milne-Edwards). Bulletin of the Marine Biological Station of Asamushi, Tohoku University, 17:191-203.

Ohsako, Y., K. Iwasaki, K. Satake, S. Sakimukai, and T. Fukutomi 1981 An example of distribution of intertidal organisms in a rocky intertidal zone near the Seto Marine Biological Laboratory of Kyoto University I. Nankiseibutsu, 23:97-102 (in Japanese).

Okada, K. and Y. Koshida 1983 Kankei-doubutsu (Annelida). In, Musekitsui-doubutsu no Hassei (Development of Invertebrates), Vol. I, Dan, K., K. Sekiguchi, Y. Andou, and H. Watanabe, (eds.), Baifukan, Tokyo, pp. 259-305.

Olive, P. J. W. 1982 Annelida - Polychaeta. In, Reproductive Biology of Invertebrates, Vol. I, Oogenesis, Oviposition and Oosorption, Adiyodi, K. G. and R. G. Adiyodi, (eds.), John Wiley and Sons, London, pp. 357-421.

Ong Che, R. G. and B. Morton 1992 Structure and seasonal variations in abundance of the macro- invertebrate community associated with Septifer virgatus (Bivalvia: Mytilidae) at Cape d'Aguilar, Hong Kong. Asian Marine Biology, 9:217-233.

Sato, M., M. Tsuchiya and M. Nishihira 1982 Ecological aspects of the development of the polychaete, Lumbrineris latreilli (Audouin et Milne-Edwards): significance of direct development and nonsimultaneous emergence of the young from the jelly mass. Bulletin of the Marine Biological Station of Asamushi, Tohoku University, 17:71-85.

Schröeder, P. C. and C. O. Hermans 1975 Annelida: Polychaeta. In, Reproduction of Marine Invertebrates, Vol. III, Annelids and Echiurans, Giese, A. C. and J. S. Pearse, (eds.), Academic Press, New York, pp. 1-213.

Seed, R. and T. H. Suchanek 1992 Population and community ecology of Mytilus. Development of Aquaculture and Fish Sciences, 25: 87-169.

Suchanek, T. H. 1985 Mussels and their role in structuring rocky shore communities. In, The Ecology of Rocky Coasts, Moore, P. G. and R. Seed, (eds.), Hodder and Stoughton, London, pp. 70-96.

Tamaki, A. 1985a Zonation by size in the Armandia sp. (Polychaeta: Opheliidae) population on an intertidal sand flat. Marine Ecology Progress Series, 27:123133.

Tamaki, A. 1985b Inhibition of larval recruitment of Armandia sp. (Polychaeta: Opheliidae) by established adults of Pseudopolydora paucibranchiata (Okuda) (Polychaeta: Spionidae) on an intertidal sand flat. Journal of Experimental Marine Biology and Ecology, 87:67-82.

Tamaki, A. 1985c Detection of non-interference within a mobile polychaete species. Journal of Experimental Marine Biology and Ecology, 90:277-287.

Tamaki, A. 1986 Current studies on species interactions and community ecology of macrobenthos in intertidal flats: a review. Japanese Journal of Ecology, 36:55-68.

Tamaki, A. 1987 Comparison of resistivity to transport by wave action in several polychaete species on an intertidal sand flat. Marine Ecology Progress Series, 37:181-189.

Tamaki, A. 1993 Characteristics of species interactions of macrobenthos in tidal flats: a summary with a perspective. In, Development of a Unified Perspective on the Organization of Communities and Ecosystems, DeAngelis, D. and E. Teramoto, (eds.), Oak Ridge National Laboratory Report, Oak Ridge, Tennessee, pp. 27-41.

Thrush, S. F. 1991 Spatial patterns in soft-bottom 
communities. Trends in Ecology and Evolution, 6:7578.

Thrush, S. F., J. E. Hewitt and R. D. Pridmore 1989 Patterns in the spatial arrangements of polychaetes and bivalves in intertidal sandflats. Marine Biology, 102:529-535.

Tokeshi, M. 1995 Polychaete abundance and dispersion patterns in mussel beds: a non-trivial 'infaunal' assemblage on a Pacific South American rocky shore. Marine Ecology Progress Series, 125:137-147.

Tokeshi, M., L. Romero, and J. Tarazona 1989 Spatial coexistence of mussel-associated free-ranging polychaetes in a subtropical intertidal habitat. Journal of Animal Ecology, 58:681-692.

Tsuchiya, M. 1979 Quantitative survey of intertidal organisms on rocky shores in Mutsu Bay, with special reference to the influence of wave action. Bulletin of the Marine Biological Station of Asamushi, Tohoku University, 16:69-86.

Tsuchiya, M. and M. Nishihira 1985 Islands of Mytilus as a habitat for small intertidal animals: effect of island size on community structure. Marine Ecology Progress Series, 25:71-81.

Tsuchiya, M. and M. Nishihira 1986 Islands of Mytilus as a habitat for small intertidal animals: effect of Mytilus age structure on the species composition of the associated fauna and community organization. Marine Ecology Progress Series, 31:171-178.
Underwood, A. J. 1978 The refutation of critical tidal levels as determinants of the structure of intertidal communities on British shores. Journal of Experimental Marine Biology and Ecology, 33:261-276.

Williams, G. B. 1964 The effect of extracts of Fucus serratus in prompting the settlement of larvae of Spirorbis borealis (Polychaeta). Journal of the Marine Biological Association of the United Kingdom, 44:397-414.

Wilson, W. H. Jr. 1981 Sediment-mediated interactions in a densely populated infaunal assemblage: the effects of polychaete Abarenicola pacifica. Journal of Marine Research, 39:735-748.

Wilson, W. H. Jr. 1983 The role of density dependence in a marine infaunal community. Ecology, 64:295-306.

Woodin, S. A. 1974 Polychaete abundance patterns in a marine soft-sediment environment: the importance of biological interactions. Ecological Monographs, 41:171-187.

Woodin, S. A. 1976 Adult-larval interactions in dense infaunal assemblages: patterns of abundance. Journal of Marine Research, 34:25-41.

\section{Address}

Keiji Iwasaki : Institute for Natural Science, Nara University, 1500 Misasagi-cho, Nara 631, Japan. 